\title{
Model Erp dan Manajemen Rantai Pasok Untuk Koperasi; Kajian Pustaka
}

\author{
Akhmad Yunani \\ Program Studi Magister Manajemen Ikopin \\ yunan06@ikopin.ac.id
}

Sistem ERP dan SCM dianggap sebagai sarana peningkatan kinerja bisnis terlepas dari jenis bisnisnya. Tulisan ini merangkum studi tentang sistem ERP dan SCM dalam bisnis koperasi. Koperasi adalah model bisnis yang unik, di mana pemiliknya juga pelanggan, pemasok, dan juga operator. Ada sedikit penelitian tentang ERP, SCM, bahkan perspektif operasi bisnis koperasi. Studi ini berfokus pada aspek teknologi, sedikit bagian dari ERP, seperti penggunaan aplikasi accouting, penggunaan pasar, dll. Makalah ini juga mengusulkan kerangka kerja model ERP dan SCM untuk koperasi. Diskusi mengacu pada standar kinerja koperasi yang ditetapkan oleh Pemerintah dan dikombinasikan dengan sistem ERP dan proses bisnis secara umum. Model ini diharapkan menjadi kerangka kerja yang cukup untuk meningkatkan kinerja koperasi serta alat kontrol bisnis koperasi. Karena berbagai jenis bisnis koperasi, disarankan agar studi lebih lanjut mengamati proses bisnis yang sebenarnya dalam koperasi sehingga sistem ERP dan model SCM dapat dikembangkan dengan baik.

Kata kunci: ERP, SCM, proses bisnis, bisnis koperasi, kinerja bisnis

Kata Kunci: ERP, SCM, Proses Bisnis.

\begin{abstract}
ERP system and SCM are considered to be the business performance enhancer regardless the business type. This paper summarizes studies on ERP systems and SCM in cooperative business. The cooperative is a unique model of business, where the owners are also customers, suppliers, as well as operators. There is a little study concerns on ERP, SCM, even operations perspective of cooperative business. If any, the study focuses on technical aspects of technology, a little part of ERP, like the use of application of accouting, the use of marketplace, etc. This paper also proposes a framework of ERP and SCM model for cooperative. The discussion refers to the performance standards of the cooperative set by the Government and combined with ERP systems and business process in general. This model is expected to be a considerable framework to enhance cooperative performance as well as a tool of control of cooperative business. Due to the vary of cooperative type of business, it is suggested that further study observes the actual business process in a cooperative so that ERP system and SCM model can be developed properly.
\end{abstract}

Keywords: ERP, SCM, business process.

\section{PENDAHULUAN}

Koperasi merupakan sebuah entitas ekonomi yang cukup unik, yakni kepemilikan dan tujuan bisnis yang melibatkan anggota. Dalam koperasi, disamping sebagai pemilik bisnis, anggota sekaligus menjadi pelaku atau aktor dalam mengoperasikan bisnis. Koperasi merupakan entitas bisnis yag bersifat kolektif untuk mencapai tujuan dari individu-individu yang tergabung di dalamnya. Dalam perspektif ideologis, model bisnis koperasi juga merupakan manifestasi konstitusi yang termaktub dalam Pasal 33 ayat (1) UUD 1945 yang menyatakan bahwa perekonomian disusun sebagai usaha bersama atas dasar kekeluargaan.

Keunikan koperasi antara lain adalah peran anggota didalam aktivitas bisnis. Pada koperasi penjualan misalnya, pemilik sekaligus merupakan pemasok yang menjual barang/jasa kepada pelanggan di mana pelanggannya adalah koperasi itu sendiri di mana pemilik menjadi anggotanya. Demikian juga pada koperasi produksi, di mana pemilik juga menjadi pekerja. Singkatnya, dalam koperasi terdapat status ganda para anggota (Hanel dalam Arifin, 2013: 30).

Sebagai sebuah sistem, ada tiga sub-sistem yang membentuk interaksi bisnis dalam koperasi. ketiga sub sistem tersebut adalah individu sebagai anggota sebagai pemilik, kelompok yang terwakili dalam rapat anggota di mana anggota merupakan representasi pemilik, dan alat untuk melaksanakan economic joint action yang disebut juga perusahaan koperasi (Arifin, 2013: 34).

Dalam konteks proses bisnis normatif, koperasi merupakan sebuah entitas bisnis yang sangat ideal 
karena informasi mengalir dengan sempurna. Supplier memeroleh informasi tentang demand dari perusahaan koperasi di mana dia sendiri merupakan bagian dari perusahaan koperasi. Informasi yang sempurna tersebut seharusnya menghasilkan efisiensi proses bisnis yang sempurna, dengan service level yang juga sempurna. Namun dalam prakteknya apakah hal ini terwujud?

\section{KOPERASI; PERAN DALAM PEREKO- NOMIAN DAN PERMASALAHANNYA}

Secara kuantitas, jumlah koperasi aktif cukup banyak dan bertumbuh positif selama 2011-2015. Jumlah koperasi aktif tumbuh sebesar 3,8 persen, dari 133.666 unit pada tahun 2011 menjadi 150.223 unit pada tahun 2015. Sedangkan jumlah anggotanya tumbuh 4,4 persen, atau sebanyak 37,78 juta anggota pada tahun 2015 (Warta Koperasi, 2016).

Ditinjau dari segi jenis usahanya, sebagian besar koperasi aktif merupakan koperasi simpan pinjam. Dominasi koperasi simpan pinjam ini bahkan sudah dimulai sejak tahun 2000. Selain menguntungkan, jenis usaha ini dinilai sangat membantu anggota koperasi dalam mengatasi masalah keuangannya dan menggalakkan semangat untuk menabung (BPS, Statistik Koperasi Simpan Pinjam 2017, 2018). Dari sisi kontribusi terhadap PDB, kontribusi koperasi terhadap PDB masih relatif kecil. Total nilai usaha koperasi di Indonesia pada tahun 2016 sebesar Rp84,86 triliun (BPS, 2018) atau hanya sebesar 0,68\% dari PDB Indonesia yang sebesar Rp12.406,8 triliun (BPS, 2017).

Meski kontribusi terhadap PDB relatif kecil, perkembangan jumlah koperasi aktif sedikitnya menunjukkan adanya peningkatan daya tarik koperasi di masyarakat. Peningkatan kiner koperasi yang ditunjukkan oleh meningkatnya volume usaha, dan sisa hasil usaha selama 2011-2015 (Warta UKM, 2016) juga merupakan cerminan peningkatan kesejahteraan anggota koperasi. Penelitian oleh Agusalim, Karim dan Yaddarabullah (2018) juga mengidentifikasi adanya peningkatan kinerja tersebut meski masih terdapat permasalahan klasik koperasi yakni tidak konsistennya pelaksanaan Rapat Umum Tahunan (RAT) dan tidak adanya manajer (yang dapat berdampak pada sistem pengelolaan koperasi secara profesional).

RAT merupakan salah satu mekanisne pengendalian dalam koperasi di mana tata kelola dan akuntabilitas kepengurusan koperasi harus dipertanggungjawabkan kepada anggota. Di samping kurangnya manajer, atau bahkan kalaupun ada manajer, permasalahan yang sering dihadapi oleh koperasi adalah bahwa manajer, pengurus, dan pengawas koperasi kurang memiliki wawasan dan kemampuan teknis untuk berproduksi, berdagang dan kemampuan manajerial untuk mengelola suatu bisnis
(Tjakrawardaja dalam Agusalim dkk, 2016). Oleh karena itu, pemahaman dan penguasaan tentang perencanaan sumber daya bagi koperasi sebagai sebuah entitas bisnis menjadi faktor penting untuk pemberdayaan koperasi.

\section{ENTERPRISE RESOURCE PLANNING (ERP); KONSEP DASAR}

Pengelolaan bisnis yang efektif membutuhkan suatu sistem yang dapat mengintegrasikan seluruh proses dan sumber daya perusahaan (enterprises) sehingga utilisasi sumber daya perusahaan diharapkan bisa memberikan value maksimal baik bagi pelanggan maupun pemilik. Bahasan tentang ERP selalu melekat dengan bahasan tentang proses bisnis.

\section{ERP dan Proses Bisnis}

Proses bisnis didefinisikan secara kontekstual oleh para ahli. Meski bervariasi, namun benang merah yang bisa ditarik adalah bahwa semuanya mengarah pada seperangkat aktivitas yang beragam untuk menghasilkan output (Bititci dan Muir, 1997). Davenport dan Short (1990) mendefinisikan proses bisnis sebagai seperangkat aktivitas saling terkait yang dilakukan mengacu pada alur logis untuk mencapai tujuan bisnis (Davenport dan Short, 1990). Menurut Davenport dan Short (1990), proses bisnis memiliki dua karakteristik penting:

- memiliki pengguna (customer), artinya proses menghasilkan sesuatu (outcome) yang digunakan oleh pihak lain. Pengguna bisa berasal dari internal perusahaan atau dari luar perusahaan.

- $\quad$ lintas fungsi, artinya proses bisnis terjadi lintas organisasi atau antar unit dalam organisasi, umumnya independen dari struktur organisasi formal.

Perumusan proses bisnis harus mencakup beberapa aspek: (1) identifikasi aktivitas bisnis, (2) identifikasi aliran informasi diantara aktivitas bisnis, (3) teknik untuk menguantifikasi relasi antar aktivitas bisnis, (4) evaluasi terhadap kuantifikasi untuk mengidentifikasi aktivitas yang berpasangan dekat, dan (5) ekstraksi kelompok aktivitas berpasangan untuk membangun model proses bisnis (Bititci dan Muir, 1997). Proses bisnis menyaratkan adanya integrasi baik dalam fungsi maupun antar fungsi (Supyuenyong dan Islam, 2009). Sistem ERP, salah satu model integrasi proses bisnis, telah banyak diimplementasikan oleh perusahaan, termasuk UKM, untuk mengintegrasikan fungsi-fungsi bisnis (penjualan, produksi, SDM, 
finansial, pembelian, dan sebagainya) perusahaan secara menyeluruh menggunakan modul-modul aplikasi berbasis proses bisnis. Disamping itu, integrasi proses bisnis juga memungkinkan untuk berbagi data, informasi, dan pengetahuan dalam perusahaan, mengotomasi elemen-elemen kritis dalam proses bisnis, dan menghasilkan dan meningkatkan aksesibilitas informasi terkini melalui basis data tunggal dan pertukaran data Invalid source specified..

Dalam konteks bisnis secara holistik, ERP mengintegrasikan proses bisnis di sepanjang rantai pasok produk/jasa. Cooper dkk (1997) secara gamblang mendefinisikan manajemen rantai pasok sebagai pengintegrasian proses bisnis dari pemakai akhir sampai para penyalur awal yang menyediakan produk, jasa dan informasi untuk menambahkan nilai bagi pelanggan. Mereka menggambarkan secara komprehensif aliran produk dan informasi di sepanjang jalur rantai pasok dari mulai pemasok paling hulu sampai dengan pelanggan paling hilir lengkap dengan integrasi proses bisnis dii dalamnya sebagai berikut.

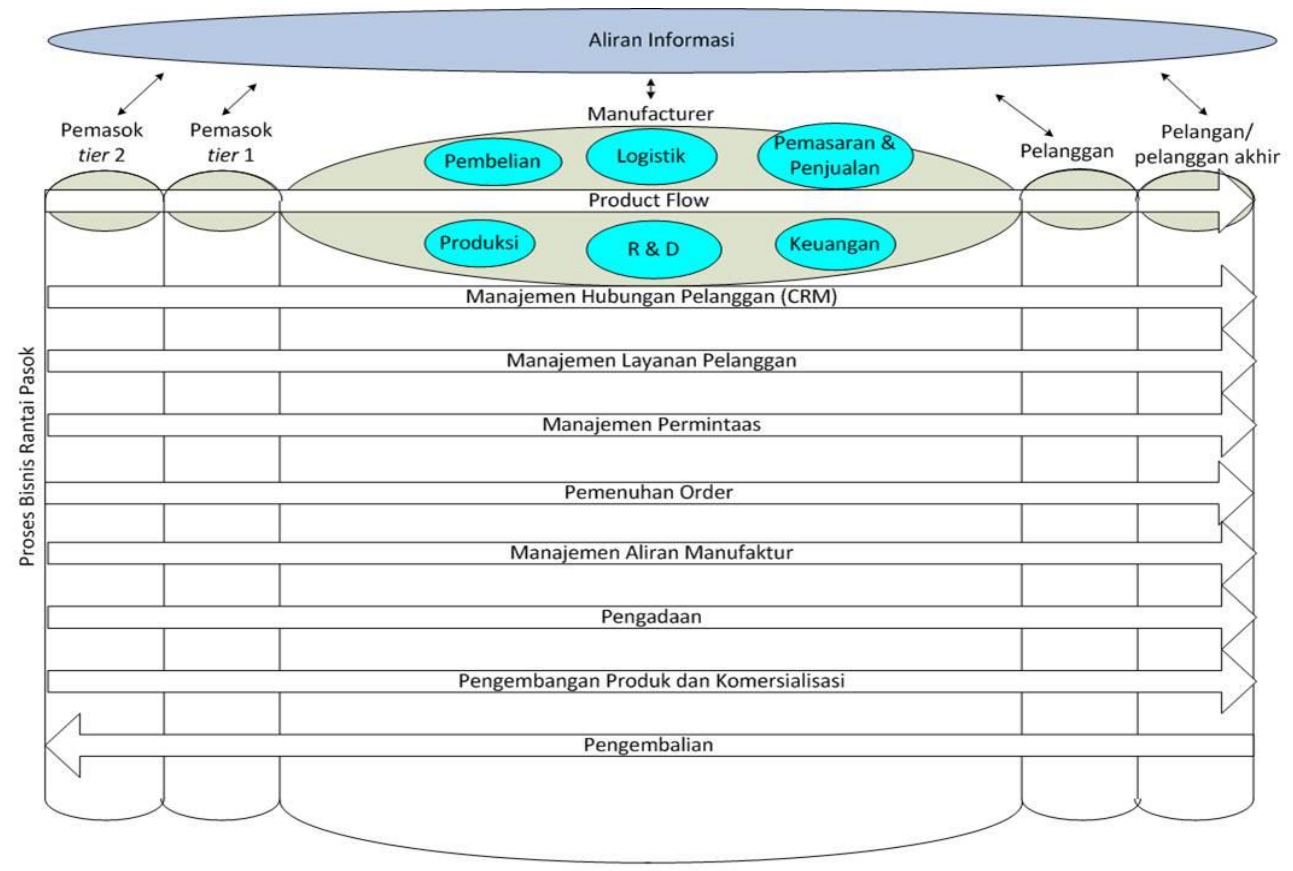

Gambar 1. Integrasi dan pengelolaan proses bisnis di sepanjang rantai pasok (Cooper dkk,

Dari gambar tersebut terlihat bahwa integrasi proses bisnis mencakup keseluruhan tier, baik upstream maupun downstream. Pelanggan, dalam proses bisnis, tetap menjadi fokus utama dalam proses. Pengendalian atas permintaan yang tak pasti, proses, dan kinerja pemasok merupakan titik-titik kritis dalam manajemen rantai pasok (Lambert dan Cooper, 2000).

\section{Prasyarat dan Perangkat ERP}

ERP merupakan sistem yang dalam implementasinya membutuhkan prasyarat dan perangkat. Sistem ERP mengacu pada proses bisnis yang baku, jelas, dan dapat dieksekusi. Quiescenti dkk (2006) menegaskan bahwa proses bisnis dan disain ERP harus mengacu pada alur kerja yang kokoh namun tetap dinamis. Hampir mirip dengan Lambert dkk (1997), Zhang dkk (2005), modul ERP dasar yang perlu dibangun perusahaan harus mencakup perencanaan produksi, purchasing, pengendalian persediaan, penjualan, pemasaran, keuangan, dan SDM.

Sistem ERP mengintegrasikan, sinkronisasi dan memadukan seluruh proses bisnis dan data/informasi menjadi sebuah informasi untuk dasar keputusan bisnis. Penggunaan hardware dan software mutlak dalam pengembangan dan implementasi ERP. Salah satu elemen terpenting dalam ERP adalah penyatuan database untuk diolah dan didistribusikan menjadi beragam modul bisnis (Malhotra dan Temponi, 2010). Oleh karena itu, infrastruktur IT merupakan tulang 
punggung dalam implementasi sistem ERP (Madanhire dan Mbohwa, 2016).

Agar efektif, penyusunan peta jalan (roadmap) implementasi ERP dan SCM mutlak harus dilakukan. Esteves (2009) mengidentifikasi ada empat tahapan untuk mewujudkan sistem ERP; persiapan, realisasi, pencapaian target, dan audit. Tahap persiapan fokus pada aktivitas yang harus harus dipersiapkan untuk mewujudkan dan mencapai benefit dan kinerja MRP. Manajer harus mampu menginisiasi dan membangun aktivitas yang terkait untuk tahap berikutnya. Dalam tahap ini juga harus terungkap apa harapan user terhadap sistem. Tahap selanjutnya, realisasi, fokus pada benefit yang didapat saat implementasi ERP. Tahap ini krusial untuk penanggung jawab operasional, organisasi, dan manajerial. Tahap berikutnya yakni pencapaian, fokus pada benefit yang telah diperoleh dari implementasi secara keseluruhan. Tahap ini bersifat strategis dan penting dalam perwujudan visi bisnis. Tahap audit menekankan pada analisis audit secara kontinyu terhadap realisasi dan benefit ERP baik sekarang maupun proyeksi kedepan.

\section{ERP DAN SCM UNTUK KOPERASI}

Dalam konteks koperasi, hampir tidak ditemukan kajian yang mengulas tentang sistem ERP dan SCM dalam ranah konsep/strategis. Artikel terkait sistem ERP dalam koperasi umumnya fokus pada level teknis, seperti yang dilakukan oleh Irawati dkk (2018). Mereka merancang sebuah sistem marketplace untuk memudahkan dan meluaskan jangkauan koperasi dalam menjual produk. Riset tersebut tidak merancang bagaimana proses bisnis di dalam koperasi dan integrasinya sampai pada informasi yang dihasilkan untuk keputusan koperasi.

\section{Proses bisnis koperasi}

Diskusi tentang proses bisnis koperasi didasarkan pada ekosistem koperasi sebagai perusahaan, atau perusahaan koperasi. oleh karena itu, diskusi proses bisnis koperasi dibagi dalam 3 kajian; perusahaan koperasi, SCM dalam koperasi, dan peta proses.

\section{a. Perusahaan koperasi}

Sebagai perusahaan, koperasi bekerja pada dua arah yaitu ke dalam dan ke luar. Arah ke dalam adalah melayani kepentingan anggota, sedangkan arah ke luar adalah interaksi koperasi dengan pasar (Arifin, 2013: 145). Pelayanan kepentingan anggota harus didefinisikan sampai pada elemen teknis terkecil dan dapat dioperasionalkan melalui alur logis yang memiliki parameter kinerja terukur. Definisi kepentingan anggota dapat dioperasionalkan jika jenis dan tujuan koperasi telah teridentifikasi. Arifin (2013:60) membedakan jenis koperasi kedalam tiga jenis, yakni koperasi pengadaan, koperasi pemasaran, dan koperasi jasa.

Koperasi pengadaan adalah koperasi yang kegiatannya mengadakan barang dan/atau jasa bagi anggotanya. Dalam hal ini, koperasi merupakan produsen atau supplier dan anggota adalah pelanggannya. Pengadaan barang dan jasa itu sendiri dapat dilakukan dengan membuat/ memproduksi (assembly) atau membeli.

Koperasi pemasaran, atau disebut juga koperasi penjualan, bertugas menampung produk-produk yang dibuat oleh anggota dan menjualnya kepada pelanggan (anggota maupun pasar eksternal). Koperasi dalam hal ini menjadi "pemimpin" untuk perkembangan harga, perubahan selera pelanggan, posisi pesaing, regulasi, dan juga riset. Sedangkan koperasi jasa memproduksi jasa untuk kepentingan anggota.

Pengelompokan jenis koperasi ini menjadi prasyarat untuk pengembangan model ERP dan SCM koperasi. Setiap jenis koperasi memiliki produk yang berbeda, proses bisnis yang berbeda, rantai nilai yang berbeda, dan sistem rantai pasok yang berbeda pula. Dengan demikian, disain sistem ERP setiap jenis koperasi akan menjadi unik sesuai dengan karakter masing-masing.

\section{b. SCM dalam koperasi}

Sebagaimana ERP, kajian tentang SCM untuk bisnis koperasi juga sulit ditemukan, berbeda dengan SCM untuk UMKM. SCM diharapkan dapat memotong proses produksi, menurunkan biaya persediaan, memperpendek lead time, meningkatkan efektivitas jaringan produk dan mempercepat distribusi. Chen dan Paulraj (2004) menguraikan manfaat SCM dalam beberapa aspek, yaitu:

standarisasi produksi. Yakni sebagai dasar penetapan kontrol kualitas, memperpendek periode produksi, dan meningkatkan efektivitas produk.

menyederhanakan proses rantai nilai. SCM digunakan untuk mengendalikan pemasok, perbaikan proses produksi, mendekatkan kepada pemasok, meingkatkan efektivitas rantai pasok, dan ketepatan waktu pasokan material dan komponen.

- mengotomasi proses. SCM dapat digunakan untuk mengurangi kesalahan proses dan memperoleh informasi tepat waktu.

- memperbaiki proses pembelian, yakni mempersingkat waktu pengiriman, dan mempercepat proses pemesanan. 
- menurunkan biaya secara keseluruhan, melalui pengurangan resiko operasi, biaya modal yang tertanam dalam persediaan dan material.

- memperbaiki proses pembayaran, yakni transaksi yang lebih cepat.

- memperbaiki proses distribusi, melalui ketepatan pemilihan pemasok jasa logistik, ketepatan waktu penyerahan, dan perbaikan manajamen distribusi secara keseluruhan.

- membangun daya saing, peluang untuk memasok pasar lebih luas.
Pemanfaatan teknologi, khususnya teknologi informasi merupakan syarat mutlak untuk membangun SCM yang ideal. Teknologi itu sendiri saat ini tersedia banyak dan dapat diperoleh dengan murah. Namun demikian masih terdapat persepsi di kalangan UMKM, bahwa teknologi terkesan mahal dan rumit. Teknologi akan menjadi murah dan memberikan kemanfaatan dalam SCM hanya apabila proses bisnis sudah tertata, karena teknologi memang hanya berfungsi sebagai penopang proses tersebut.

Sebagaimana ERP, disain SCM untuk koperasi juga harus mengacu pada proses bisnis yang melekat pada koperasi itu sendiri. Untuk koperasi yang kegiatan usahanya memproduksi barang (manufacturing), alternatif model SCM dapat dirumuskan sebagai berikut.

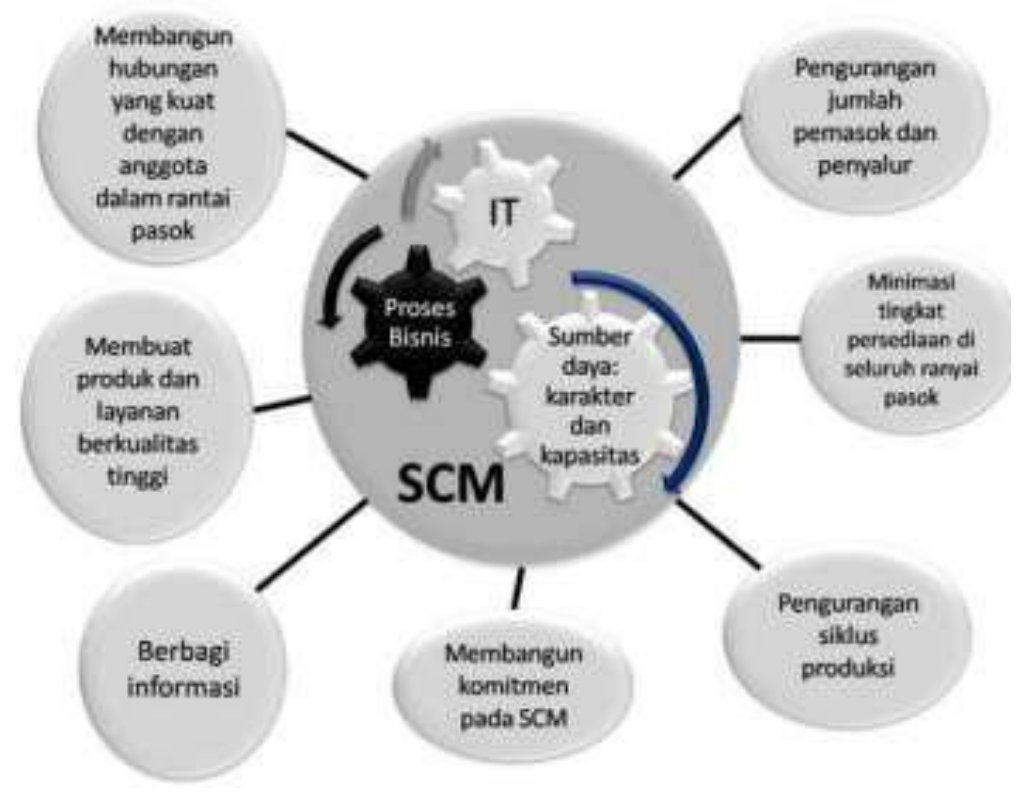

Gambar 2. Alternatif Model SCM Koperasi Produsen

Gambar tersebut menjelaskan bahwa sebelum model dibangun, proses harus terlebih dahulu didefinisikan. Luaran utama model berupa proses bisnis pengelolaan penjualan dari mulai administrasi order sampai dengan pelaporan akuntansinya, procurement dari mulai pembuatan order pembelian sampai dengan pengelolaan gudang material beserta akuntansinya, pengelolaan persediaan, penjadwalan produksi dan pengelolaan gudang produk jadi.

Gambar tersebut juga menjelaskan bahwa tujuan SCM adalah efisiensi dan efektivitas operasi yang dituangkan dalam tujuh kerangka rantai pasok. Ketujuh kerangka tersebut dapat terbangun dengan menata terlebih dahulu proses bisnis, ditopang dengan teknologi, dan mendasarkan pada karakter dan kapasitas sumber daya dalam sistem rantai pasok. Kerangka pemodelan tersebut mendasari alasan dilakukannya penelitian ini, dan merupakan pijakan untuk menyusun langkah-langkah yang akan dilakukan dalam penelitian beserta ukuran luarannya.

\section{c. Peta proses}

Peta proses diperlukan untuk mendisain proses bisnis yang diperlukan untuk landasan ERP dan SCM koperasi. Peta proses menggambarkan hubungan antara aktivitas, data, dan obyek yang terlibat dalam memproduksi suatu output (Biazzo, 2002).

Sebelum merancang peta proses, koperasi perlu menetapkan outcome, ukuran output dan ukuran proses untuk mewujudkan outcome. Sebagai contoh, sebuah koperasi beranggotakan pengelola kedai kopi dengan tujuan utama adanya jaminan untuk memeroleh bahan baku kopi secara kontinyu dengan harga terbaik. Outcome, output dan proses beserta ukurannya bisa dirumuskan sebagai berikut: 
Tabel 1. Contoh rumusan outcome, output dan proses sebagai landasan peta proses

\begin{tabular}{|c|c|c|}
\hline Outcomes & Ukuran output & Ukuran proses \\
\hline $\begin{array}{l}\text { 1. Ketersediaan } \\
\text { pasokan }\end{array}$ & $\begin{array}{l}\text { Jumlah } \\
\text { persediaan } \\
\text { rata-rata } \\
\text { anggota per } \\
\text { minggu }\end{array}$ & $\begin{array}{l}\text { Jumlah aktivitas } \\
\text { yang dilakukan } \\
\text { untuk } \\
\text { menyimpan kopi } \\
\text { Jumlah data } \\
\text { yang diperlukan } \\
\text { untuk } \\
\text { menghitung } \\
\text { persediaan kopi } \\
\text { Waktu } \\
\text { diperlukan } \\
\text { untuk } \\
\text { menghitung } \\
\text { persediaan }\end{array}$ \\
\hline $\begin{array}{l}\text { 2. Biaya perolehan } \\
\text { kopi }\end{array}$ & $\begin{array}{l}\text { Harga beli } \\
\text { kopi per kg }\end{array}$ & $\begin{array}{l}\text { Jumlah aktivitas } \\
\text { yang dilakukan } \\
\text { untuk } \\
\text { mendapatkan } \\
\text { pasokan kopi } \\
\text { - Jumlah orang } \\
\text { dilibatkan untuk } \\
\text { mencari } \\
\text { pemasok }\end{array}$ \\
\hline 3. Lead time & $\begin{array}{l}\text { Waktu aktual } \\
\text { untuk } \\
\text { mendapatkan } \\
\text { pasokan kopi }\end{array}$ & $\begin{array}{l}\text { Jumlah aktivitas } \\
\text { yang dilakukan } \\
\text { untuk } \\
\text { pengiriman } \\
\text { Jumlah moda } \\
\text { angkutan yang } \\
\text { dilibatkan untuk } \\
\text { pengiriman } \\
\text { pesanan kopi }\end{array}$ \\
\hline
\end{tabular}

Matriks outcomes, output, dan proses memudahkan koperasi merancang peta proses. Peta proses dirancang mengacu pada jenis koperasi, dengan enam alur berikut (Swink dkk, 2011: 93):

- Tetapkan outcome bisnis yang diinginkan untuk setiap proses beserta ukuran pencapaiannya

- Identifikasi dan batasi proses kritis

- Dokumentasikan proses saat ini (current state map)

- Analisi proses dan identifikasi peluang perbaikan

- Rekomendasikan perubahan proses yang memungkinkan (future state map)

- Implementasikan perubahan dan monitor perbaikan

\section{Kinerja koperasi}

Kinerja koperasi diukur dalam beberapa dimensi pengukuran. Mengacu pada Permen KUKM Nomor 21/Per/M.KUKM/IX/2015 Tentang Pemeringkatan Koperasi, peringkat (indikator kinerja) koperasi mencakup lima aspek; kelembagaan, usaha, keuangan, manfaat terhadap anggota, dan manfaat terhadap masyarakat.
Sebagai perusahaan yang memiliki dua arah, kinerja koperasi diukur berdasarkan kemampuannya memenuhi kepentingan anggota dan pengukuran kinerja bisnis yang bisa mengacu pada pengukuran kinerja rantai pasok. Perpaduan rumusan kinerja rantai pasok yang dikemukakan oleh Beamon (1999), Kleijnen (2003), dan SCOR ${ }^{\circledR}$ Model (yang dikembangkan oleh Supply Chain Council - SCC) dapat dirangkum sebagai berikut:

Tabel 2. Rumusan kinerja rantai pasok beserta indikatornya

\begin{tabular}{|c|c|}
\hline Dimensi & Indikator \\
\hline \multirow[t]{2}{*}{ 1. Keandalan } & $\begin{array}{l}\text { 1. Kemampuan memenuhi } \\
\text { order tepat waktu }\end{array}$ \\
\hline & $\begin{array}{l}\text { 2. Kecenderungan repeat } \\
\text { order }\end{array}$ \\
\hline $\begin{array}{ll}\text { 2. } & \text { Responsiveness }\end{array}$ & $\begin{array}{l}\text { Kecepatan memberikan } \\
\text { tanggapan terhadap order }\end{array}$ \\
\hline \multirow[t]{2}{*}{ 3. $\quad$ Fleksibilitas } & $\begin{array}{l}\text { 1. Kecederungan terjadinya } \\
\text { stock-out }\end{array}$ \\
\hline & $\begin{array}{l}\text { 2. Kecederungan terjadinya } \\
\text { lost sale }\end{array}$ \\
\hline \multirow[t]{3}{*}{ 4. $\quad$ Biaya } & $\begin{array}{l}\text { 1. Eskalasi biaya } \\
\text { keseluruhan }\end{array}$ \\
\hline & $\begin{array}{l}\text { 2. Eskalasi harga pokok } \\
\text { produksi }\end{array}$ \\
\hline & $\begin{array}{l}\text { 3. Eskalasi biaya untuk } \\
\text { memenuhi order pelanggan }\end{array}$ \\
\hline \multirow[t]{2}{*}{ 5. $\quad$ Aset } & $\begin{array}{l}\text { 1. Eskalasi perputaran modal } \\
\text { kerja }\end{array}$ \\
\hline & $\begin{array}{l}\text { 2. Efektivitas penggunaan } \\
\text { aktiva }\end{array}$ \\
\hline
\end{tabular}

Beragam dimensi pengukuran kinerja di atas dapat dirujuk untuk merancang ukuran kinerja koperasi yang nantinya menjadi acuan dalam perumusan sistem ERP dan SCM.

\section{Usulan model}

Mengacu pada beberapa literatur yang dibahas sebelumnya, rumusan sistem ERP koperasi yang diajukan tergambar sebagai berikut: 


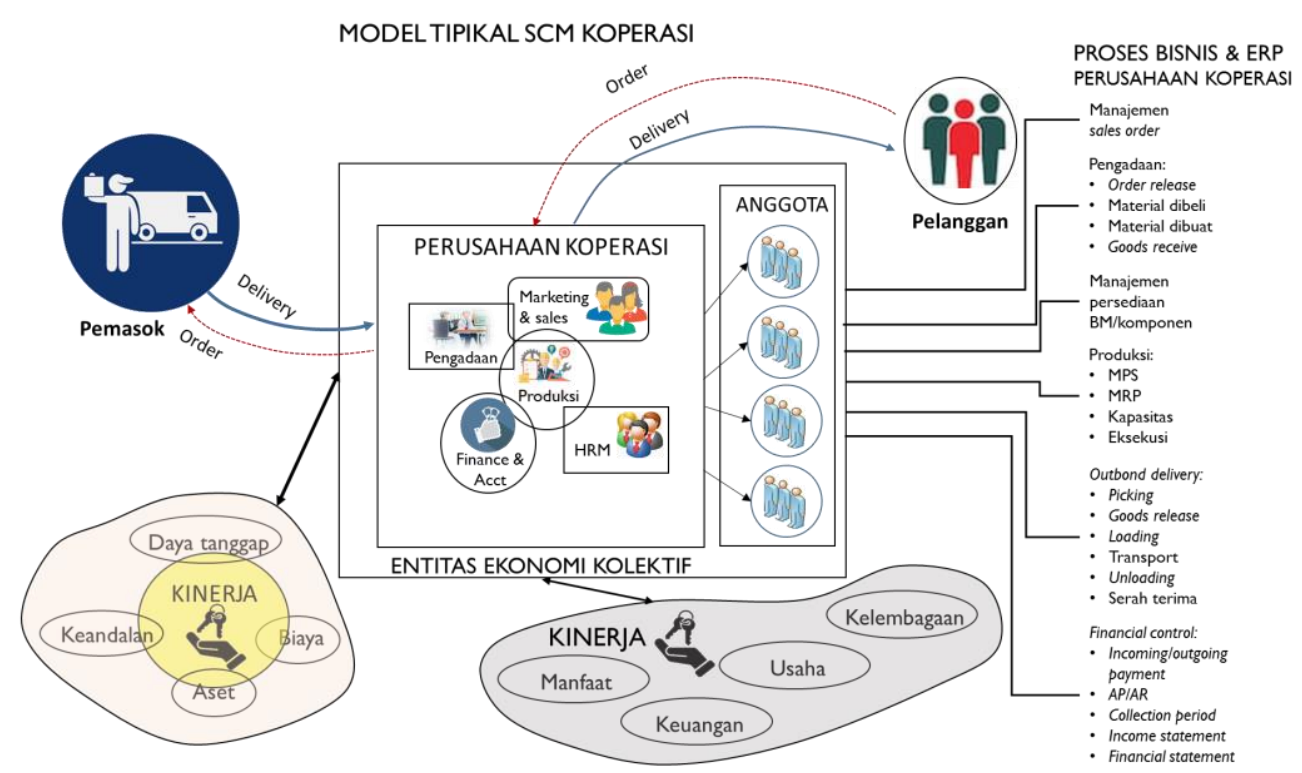

Gambar 3. Rumusan sistem ERP dan model SCM

Gambar di atas menjelaskan bahwa proses bisnis koperasi dibangun dari dua karakter yakni sebagai entitas ekonomi kolektif dan sebagai perusahaan. Sebagai entitas ekonomi, proses bisnis dan ERP berkaitan dengan pemenuhan kesejahteraan anggota sebagai outcome. Sedangkan outcome sebagai perusahaan adalah terpenuhinya ekspektasi pelanggan dengan biaya yang efisien. Kinerja koperasi bisa diukur menggunakan framework SCM maupun mengacu kapda KepmenKUKM Nomor 21 Tahun 2015.

Output dan proses koperasi baik dalam rangka memenuhi kesejahteraan anggota maupun mencapai tujuan bisnis sebagai perusahaan mencakup manajemen sales, pengadaan, manajemen persediaan, aspek produksi, delivery, dan pengendalian keuangan. Enam aspek tersebut ditambah aspek sumber daya manusia (Human Resource Management - HRM) merupakan inti dari proses bisnis koperasi. Proses tersebut selanjutnya dapat dibuat peta proses untuk perancangan integrasi proses dan sumber daya koperasi.

\section{KESIMPULAN}

Koperasi merupakan entitas bisnis yang unik, di mana anggota berperan sebagai pemilik, pemasok, pelanggan, dan sekaligus operator bisnis. Permasalahan mendasar dan umum dalam koperasi adalah kesenjangan manajerial. Sebagai entitas ekonomi kolektif, tujuan utama koperasi adalah kesejahteraan anggota. Sebagai perusahaan, layaknya perusahaan yang berorientasi profit, tujuan koperasi adalah pemupukan profit.
Sampai saat ini belum ditemukan kajian komprehensif tentang pemodelan ERP dan SCM untuk koperasi. Sebelum mengembangkan sistem ERP, koperasi harus merancang proses bisnis dan outcome yang jelas beserta ukuran output dan prosesnya. Outcome harus mencerminkan peran koperasi sebagai entitas ekonomi kolektif yang bertujuan meningkatkan kesejahteraan anggota sekaligus sebagai perusahaan yang harus memproduksi barang/jasa untuk memenuhi ekspektasi pelanggan secara efisien. Model SCM akan memudahkan koperasi untuk merumuskan proses bisnis tersebut.

\section{SARAN}

Penelitian lebih lanjut diperlukan untuk merumuskan sistem ERP dan model SCM yang lebih teknis. Agar model tersebut implementatif, observasi dan studi kasus disarankan untuk pengembangan model mengingat karakter setiap koperasi berbeda.

\section{DAFTAR PUSTAKA}

Agusalim, L. M. (2018). Analisis Perkembangan, Kinerja, dan Daya Saing Koperasi Indonesia Dalam Pembangkitan Ekonomi. SEMINAR NASIONAL \& KONGRES ISEI XX (pp. 2-15). Bandung: ISEI Jawa Barat.

Arifin, R. (2013). Koperasi Sebagai Perusahaan. Sumedang: Ikopin Press.

Biazzo, S. (2002). Process mapping techniques and organisational analysis; Lessons from sociotechnical system theory. Business Process Management Journal, Vol. 8 No. 2, 42-52. 
Bititci, Umit S. dan Daniel Muir. (1997). Business process definition: a bottom-up approach. International Journal of Operations \& Production Management, Vol. 17 No. 4, (pp. 365-374).

BPS. (2017). Pertumbuhan Ekonomi Indonesia Tahun 2016. Jakarta: Badan Pusat Statistik.

BPS. (2018). Statistik Koperasi Simpan Pinjam 2017. Jakarta: Badan Pusat Statistik.

BPS. (2018). Volume Usaha Koperasi Menurut Volume 2006-2016. Jakarta: Biro Pusat Statistik.

Irawati, Dyah Ayu, Felix David, Ekojono, dan Yushintia Pramitarini. (2018). Desain Model Sistem Marketplace Untuk Koperasi di Indonesia. Seminar Nasional Informatika 2018 (pp. 184-195). Yogyakarta: Universitas Veteran.

Chen, Injazz J. dan Antorny Paulraj. (2004). Towards a theory of supply chain management: the constructs and measurements. Journal of Operations Management, Vol. 22 Issue 2, (pp. 119-150).

Cooper, Martha C., Douglas M. Lambert, dan Janus D. Pagh. (1997). Supply Chain Management: More Than a New Name for Logistics. International Journal of Logistics Management, Vol. 8 Iss: 1, (pp. 1-14).

Davenport, Thomas H. dan James E. Short. (1990). The new industrial engineering: Information technology and business process redesign. Sloan Management Review, Vol. 31 No. 4, (pp. 1-31).

Esteves, J. (2009). A benefits realisation road-map framework for ERP usage in small and medium-sized enterprises. Journal of Enterprise Information Management, Vol. 22 No. 1/2, 25-35.

Kemen KUKM. (2015). Peraturan Menteri KUKM Nomor 21/Per/M.KUKM/IX/2015. Jakarta: Kemen KUKM.

KemenKUM. (2016). Penguatan UMKM Untuk Pertumbuhan Ekonomi yang Berkualitas. Warta KUMKM; Vol. 5 No. 1, pp. 3-35.

Lambert, Douglas M., Martha C. Cooper. (2000). Issues in Supply Chain Management. Industrial Marketing Management, Vol. 29, (pp. 65-83).

Madanhire, Ignatio dan Charles Mbohwa. (2016). Enterprise resource planning (ERP) in improving operational efficiency: Case study. 13th Global Conference on Sustainable Manufacturing - Decoupling Growth from
Resource Use (pp. 225-229). Johannesberg: Elsevier B.V.

Malhotra, Rajiv dan Cecilia Temponi. (2010). Critical decisions for ERP integration: Small business issues. International Journal of Information Management, Vol. 30, 28-37.

Quiescenti, M., Manfredi Bruccoleri, S. Noto La Diega, Giovanni Perrone, dan Umberto La Commare. (2006). Business process-oriented design of Enterprise Resource Planning (ERP) systems for small and medium enterprises. nternational Journal of Production Research, Volume 44, Issue 18-19, 3797-3811.

Supyuenyong, Varintorn dan Nazrul Islam. (2009). Influence of SME characteristics on knowledge management processes. Journal of Enterprise Information Management, Vol. 22 No. 1/2, (pp 63-80).

Swink, Morgan, Steven A. Melnyk, M. Bixby Cooper, dan Janet L. Hartley Morgan. (2011). Managing Operations Across the Supply Chain. New York: McGraw-Hill.

Zhang, Zhe, Matthew K.O. Lee, Pei Huang, Liang Zhang, dan Xiaoyuan Huang. (2005). A framework of ERP systems implementation success in China: An empirical study. International Journal of Production Economics, Vol. 98, 56-80. 